\title{
Performance Evaluation of Arc Ash Melting Systems by Computational Simulation
}

\author{
Hideya NISHIYAMA, Toshiki SHIMIZU11 and Takehiko SATO \\ Institute of Fluid Science, Tohoku University, 2-1-1, Katahira, Aoba-ku, Sendai 980-8577 Japan. \\ 1) Mitsubishi Heavy Industries, Ltd., 1-8-1, Sachiura, Kanazawa-ku, Yokohama 236-0003 Japan.
}

(Received on July 22, 2003; accepted in final form on October 2, 2003)

\begin{abstract}
For the optimization of arc ash melting process, present study has proposed the new numerical model to consider the arc-electrodes boundary condition without assumptions and also the complex interactions between the arc flow and molten soil interface with phase change. The effects of arc current, inlet gas flow rate, electrode gap and cathode vertex angle on the thermofluid field and net effective process efficiency of arc-ash melting systems are clarified by computational simulation.
\end{abstract}

KEY WORDS: arc; ash melter; complex interaction; process efficiency; computational simulation.

\section{Introduction}

Since arc has the advantages of stable and controllable heating, it has been extensively utilized as a heat source for welding, cutting, metallurgical processings and further in the waste treatment. ${ }^{1)}$ In recent years, the needs for arc ash melting systems are increasing to reduce the ash to smaller volume, to promote the stability of ash behavior and to reduce dioxins. ${ }^{2)}$ By using these systems, we can reduce the waste volume considerably and separate the evaporated heavy metals and further seal up it into the slag with glass phase. ${ }^{3)}$ However, there have been rising the problems about electric power consumption, electrode cost and safety for secondary hazardous matter. Then, the increase in melting efficiency and sealing up, waste minimization, electric power reduction and further longer life for electrode and melter are required eagerly.

Since arc ash melting process includes the complex interaction between the arc flow and molten soil interface, experimental work is rather limited for determining the optimum operating conditions in the arc ash melter. Then, computational simulation is effective method to optimize the arc ash melting systems. ${ }^{4-7)}$

In the present study, numerical modeling is conducted for arc ash melting process to consider the arc-electrodes boundary conditions without empirical assumptions and complex interaction between arc and molten soil interface with phase change. ${ }^{8)}$ The effects of arc current, inlet flow rate, electrode gap and cathode geometry on heat transfer and fluid flow in the molten pools are numerically clarified relating to complex electromagnetic heat and fluid flow. Finally, the net effective soil heating efficiency and ash melting volume fraction for those parameters are evaluated for optimization of arc ash melting process.

\section{Numerical Modeling}

Figure 1 shows a schematic illustration of arc ash melting systems and the coordinate systems. In order to derive the governing equations, the following assumptions are introduced here.

(1) A steady, 2D axisymmetric, and laminar arc flow and molten pool flow are prevailed.

(2) Argon arc is optically thin in local thermodynamic equilibrium (LTE) state.

(3) There are temperature dependent thermodynamic and transport properties.

(4) Melting, evaporation and deformation on electrodes are not considered.

(5) Evaporation, deformation, electric charge and surface

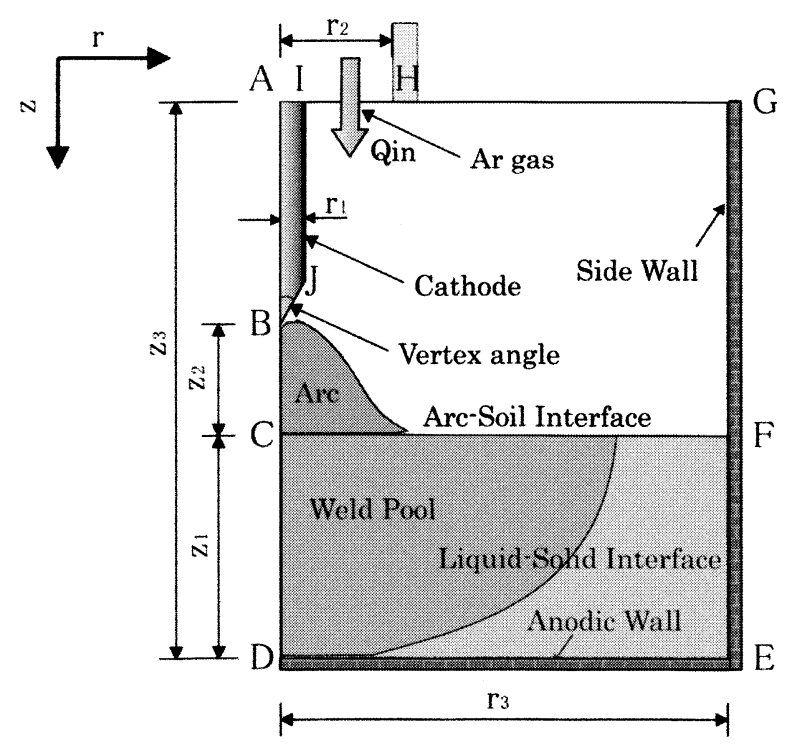

Fig. 1. Schematic illustration of arc ash melting systems and the coordinate systems 
tension at arc-soil interface are not considered.

(6) Radiation from cathode, reactor wall and arc-soil interface are not considered.

(7) The gravitational force, viscous dissipation and compressed work are neglected.

(8) The induction magnetic field has an axisymmetrical and azimuthal component.

Under these assumptions, the governing equations are presented as follows:

Conservation of mass (arc, soil)

$$
\frac{\partial}{\partial z}(\rho u)+\frac{1}{r} \frac{\partial}{\partial r}(r \rho v)=0
$$

Conservation of momentum (arc, soil)

$$
\begin{aligned}
& \frac{\partial}{\partial z}(\rho u u)+\frac{1}{r} \frac{\partial}{\partial r}(r \rho u v) \\
& =-\frac{\partial p}{\partial z}+2 \frac{\partial}{\partial z}\left(\eta_{\mathrm{Ar}, \text { Soil }} \frac{\partial u}{\partial z}\right)+\frac{1}{r} \frac{\partial}{\partial r}\left(r \eta_{\mathrm{Ar}, \text { Soil }}\left(\frac{\partial u}{\partial r}+\frac{\partial v}{\partial z}\right)\right) \\
& -\frac{2}{3} \frac{\partial}{\partial z}\left(\eta_{\mathrm{Ar}, \text { Soil }}\left(\frac{\partial u}{\partial z}+\frac{1}{r} \frac{\partial(r v)}{\partial r}\right)\right)+j_{r} B_{\theta}+\rho g \ldots . .(2) \\
& \frac{\partial}{\partial z}(\rho v u)+\frac{1}{r} \frac{\partial}{\partial r}(r \rho v v) \\
& =-\frac{\partial p}{\partial r}+\frac{\partial}{\partial z}\left(\eta_{\mathrm{Ar}, \text { Soil }}\left(\frac{\partial v}{\partial z}+\frac{\partial u}{\partial r}\right)\right)+\frac{2}{r} \frac{\partial}{\partial r}\left(r \eta_{\mathrm{Ar}, \text { Soil }} \frac{\partial v}{\partial z}\right) \\
& \quad-\frac{2}{3} \frac{\partial}{\partial r}\left(\eta_{\mathrm{Ar}, \text { Soil }}\left(\frac{\partial u}{\partial z}+\frac{1}{r} \frac{\partial(r v)}{\partial r}\right)\right)-\eta_{\mathrm{Ar}, \text { Soil }} \frac{2 v}{r^{2}}-j_{z} B_{\theta} .
\end{aligned}
$$

Conservation of energy

in the arc:

$$
\begin{aligned}
& \frac{\partial}{\partial z}(\rho h u)+\frac{1}{r} \frac{\partial}{\partial r}(r \rho h v) \\
& =\frac{\partial}{\partial z}\left(\frac{\lambda_{\mathrm{Ar}}}{C_{\mathrm{p}(\mathrm{Ar})}} \frac{\partial h}{\partial z}\right)+\frac{1}{r} \frac{\partial}{\partial r}\left(\frac{r \lambda_{\mathrm{Ar}}}{C_{\mathrm{p}(\mathrm{Ar})}} \frac{\partial h}{\partial r}\right)+\frac{j_{z}^{2}+j_{r}^{2}}{\sigma_{\mathrm{Ar}}} \\
& \quad+\frac{5}{2} \frac{k_{\mathrm{b}}}{e}\left(\frac{j_{z}}{C_{\mathrm{p}(\mathrm{Ar})}} \frac{\partial h}{\partial z}+\frac{j_{r}}{C_{\mathrm{p}(\mathrm{Ar})}} \frac{\partial h}{\partial r}\right)-R a \ldots \ldots . . .
\end{aligned}
$$

in the soil:

$$
\begin{aligned}
& \frac{\partial}{\partial z}(\rho h u)+\frac{1}{r} \frac{\partial}{\partial r}(r \rho h v) \\
& =\frac{\partial}{\partial z}\left(\frac{\lambda_{\text {Soil }}}{C_{\mathrm{p}(\text { Soil })}} \frac{\partial h}{\partial z}\right)+\frac{1}{r} \frac{\partial}{\partial r}\left(\frac{r \lambda_{\text {Soil }}}{C_{\mathrm{p}(\text { Soil }}} \frac{\partial h}{\partial r}\right)+\frac{j_{z}^{2}+j_{r}^{2}}{\sigma_{\text {Soil }}}
\end{aligned}
$$

inside the cathode:

$$
\frac{\partial}{\partial z}\left(\frac{\lambda_{\mathrm{C}}}{C_{\mathrm{p}(\mathrm{C})}} \frac{\partial h}{\partial z}\right)+\frac{1}{r} \frac{\partial}{\partial r}\left(\frac{r \lambda_{\mathrm{C}}}{C_{\mathrm{p}(\mathrm{C})}} r \frac{\partial h}{\partial r}\right)+\frac{j_{z}^{2}+j_{r}^{2}}{\sigma_{\mathrm{C}}}=0
$$

Table 1. Geometry and operating conditions of arc ash melting systems.

\begin{tabular}{ll}
\hline $\begin{array}{l}\text { Operating pressure } \\
\text { Arc current }\end{array}$ & $\begin{array}{l}p_{0}=1.01 \times 10^{5} \quad(\mathrm{~Pa}) \\
\text { Argon flow rate }\end{array}$ \\
Cathode radius & $Q_{i n}=100,300,500 \quad(\ell / \mathrm{min})$ \\
Nozzle radius & $r_{1}=12 \quad(\mathrm{~mm})$ \\
Melter radius & $r_{2}=36 \quad(\mathrm{~mm})$ \\
Electrode vertex angle & $r_{3}=400 \quad(\mathrm{~mm})$ \\
Soil depth & $z_{1}=30^{\circ}, 60^{\circ}, 190^{\circ}$ \\
Electrode gap & $z_{1}+z_{2}=225,275,300 \quad(\mathrm{~mm})$ \\
Axial length & $z_{3}=450 \quad(\mathrm{~mm})$ \\
\hline
\end{tabular}

Equation of state

$$
p=\rho R T
$$

Conservation of electric current (all regions)

$$
\frac{\partial}{\partial z}\left(\sigma_{\text {Ar, C,Soil }} \frac{\partial}{\partial z} \phi\right)+\frac{1}{r} \frac{\partial}{\partial r}\left(r \sigma_{\text {Ar, }, \text { Soil }} \frac{\partial}{\partial r} \phi\right)=0
$$

Ohmic equation (all regions)

$$
\begin{aligned}
& j_{z}=-\sigma_{\text {Ar, }, \text { Soil }} \frac{\partial \phi}{\partial z} \\
& j_{r}=-\sigma_{\text {Ar, C,Soil }} \frac{\partial \phi}{\partial r}
\end{aligned}
$$

Ampere's rule

$$
\frac{1}{r} \frac{\partial}{\partial r}\left(r B_{\theta}\right)=\mu_{0} j_{z}
$$

Table 1 shows the geometry and operating conditions of arc ash melting systems.

The boundary conditions in the arc, cathode, soil regions, interface between arc and soil are given here without any assumptions on the cathode. . $^{\text {) }}$

Arc and cathode region:

axis $\mathrm{AB}: \quad \frac{\partial T}{\partial r}=0, \frac{\partial \phi}{\partial r}=0$

axis $\mathrm{BC}: \quad \frac{\partial T}{\partial r}=0, \frac{\partial \phi}{\partial r}=0, \frac{\partial u}{\partial r}=v=0$

wall FG: $\quad T=1000 \mathrm{~K}, \frac{\partial \phi}{\partial r}=0, \quad u=v=0$

exit GH: $\quad \frac{\partial^{2} T}{\partial z^{2}}=0, \quad \frac{\partial \phi}{\partial z}=0, \quad \frac{\partial u}{\partial z}=v=0$

inlet HI: $\quad T=300 \mathrm{~K}, \frac{\partial \phi}{\partial z}=0, \quad u=u_{\text {in }}, \quad v=0$

cathode root IA: $\quad T=300 \mathrm{~K},-\sigma_{\mathrm{C}} \frac{\partial \phi}{\partial z}=j_{\text {in }}$

cathode surface IJB: $u=v=0$ 
Soil region:

axis CD: $\quad \frac{\partial T}{\partial r}=0, \frac{\partial \phi}{\partial r}=0, \frac{\partial u}{\partial r}=v=0$

bottom anode surface DE: $T=1000 \mathrm{~K}, \phi=0, u=v=0$

wall EF: $\quad T=1000 \mathrm{~K}, \frac{\partial \phi}{\partial r}=0, u=v=0$

Interface $\mathrm{CF}$ :

molten state:

$-\lambda_{\mathrm{p}} \frac{\partial T_{\mathrm{p}}}{\partial z}=\lambda_{\text {Soil }} \frac{\partial T_{\text {Soil }}}{\partial z}, \quad-\eta_{\mathrm{p}} \frac{\partial v_{\mathrm{p}}}{\partial z}=\eta_{\text {Soil }} \frac{\partial v_{\text {Soil }}}{\partial z}, \quad u=0$

solid state: $\quad-\lambda_{\mathrm{p}} \frac{\partial T_{\mathrm{p}}}{\partial z}=\lambda_{\text {Soil }} \frac{\partial T_{\text {Soil }}}{\partial z}, \quad u=v=0$

The criterion for phase change of soil is given here.

solid state: $\quad T_{\text {Soil }} \leq T_{\text {melt }}=1428 \mathrm{~K}$

molten state: $\quad T_{\text {Soil }}>T_{\text {melt }}$

Thermodynamic and transport properties of argon, cathode of black lead and soil are given as a function of temperature. $^{10-14)}$ Each governing equation is solved by SIMPLE Method. ${ }^{15)}$

(a)
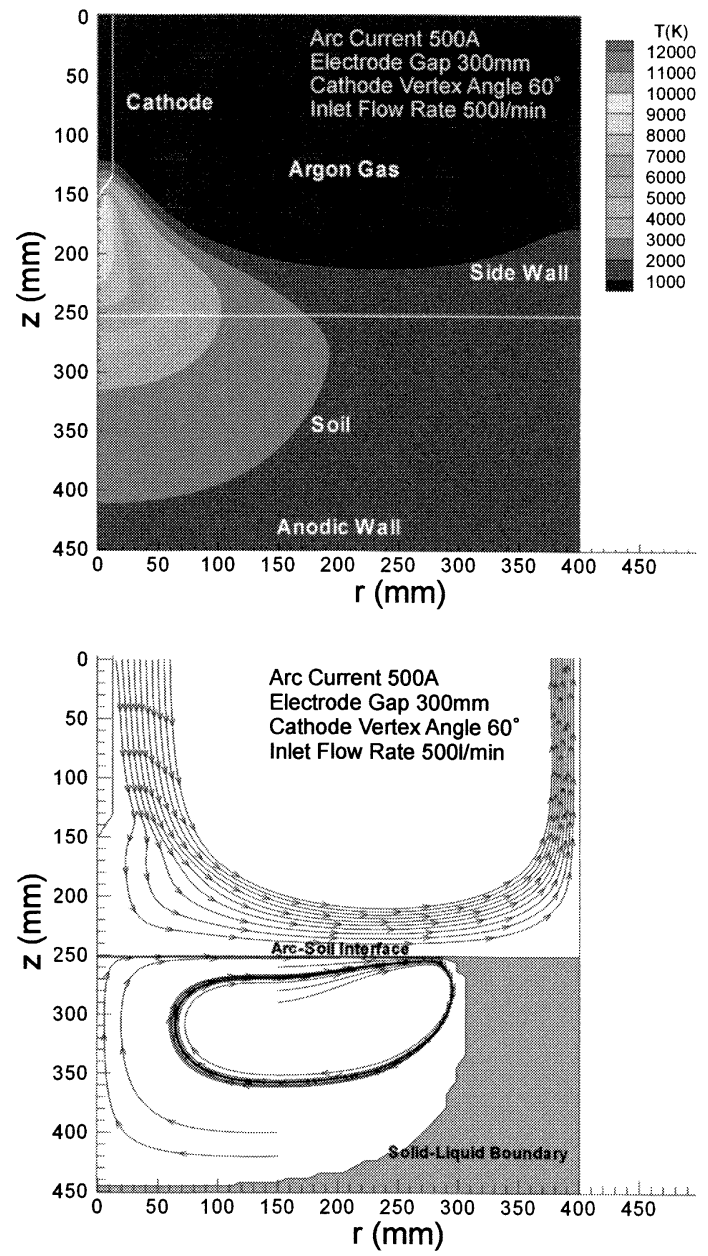

\section{Numerical Results and Discussion}

Figures 2(a) and 2(b) show the effect of arc current on the isotherm, stream line, arc-soil interface and solidliquid boundary in the arc melter. The input currents are $500 \mathrm{~A}$ and $2000 \mathrm{~A}$ respectively, electrode gap: $300 \mathrm{~mm}$, flow rate: $500 \mathrm{~L} / \mathrm{min}$ and cathode vertex angle is $60^{\circ}$. At the operating current of $2000 \mathrm{~A}$ in Fig. 2(b), the maximum temperature increases due to the active Joule heating in the arc, and also arc impinging velocity towards the soil interface increases due to the strong radial and axial Lorentzian forces. Then, the shear force at the arc-soil interface and the boyancy in the molten pool increase. Finally, since the thermal conduction from arc to the soil interface and further Joule heating and convective heat transfer in the molten pool increase, molten soil volume also increases.

Figures 3(a) and 3(b) show the effect of electrode gap on the isotherm, streamline, arc-soil interface and solid-liquid boundary. Since both thermal conduction to the arc-soil interface and convective heat transfer decrease due to the smaller arc volume and imping velocity, molten soil volume also decrease at the electrode gap of $225 \mathrm{~mm}$ in Fig. 3(b). On the other hand, the radiation loss from the large arc volume increases at larger electrode gap in Fig. 3(a).

Figures 4(a) and 4(b) show the effect of inlet flow rate on the ash melting process. Since the impinging flow with

(b)
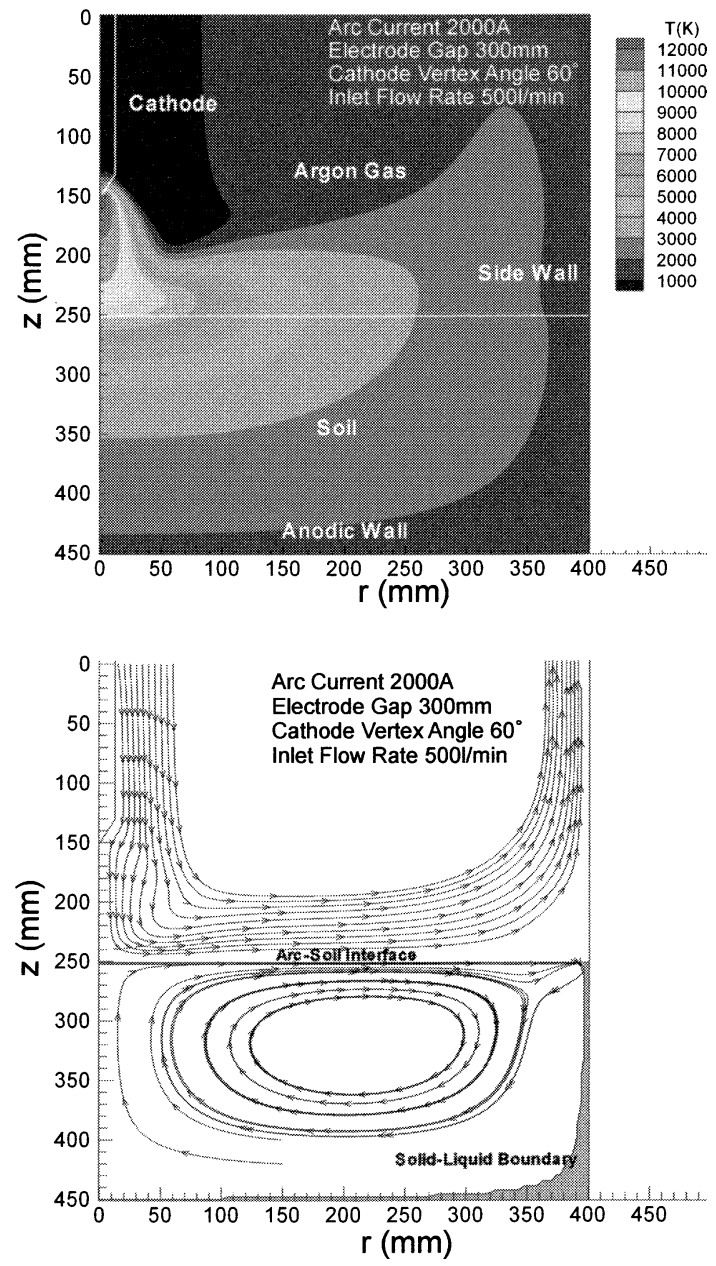

Fig. 2. Effect of arc current on isotherm, streamline, arc-soil interface and solid-liquid boundary in the arc melter. 
(a)
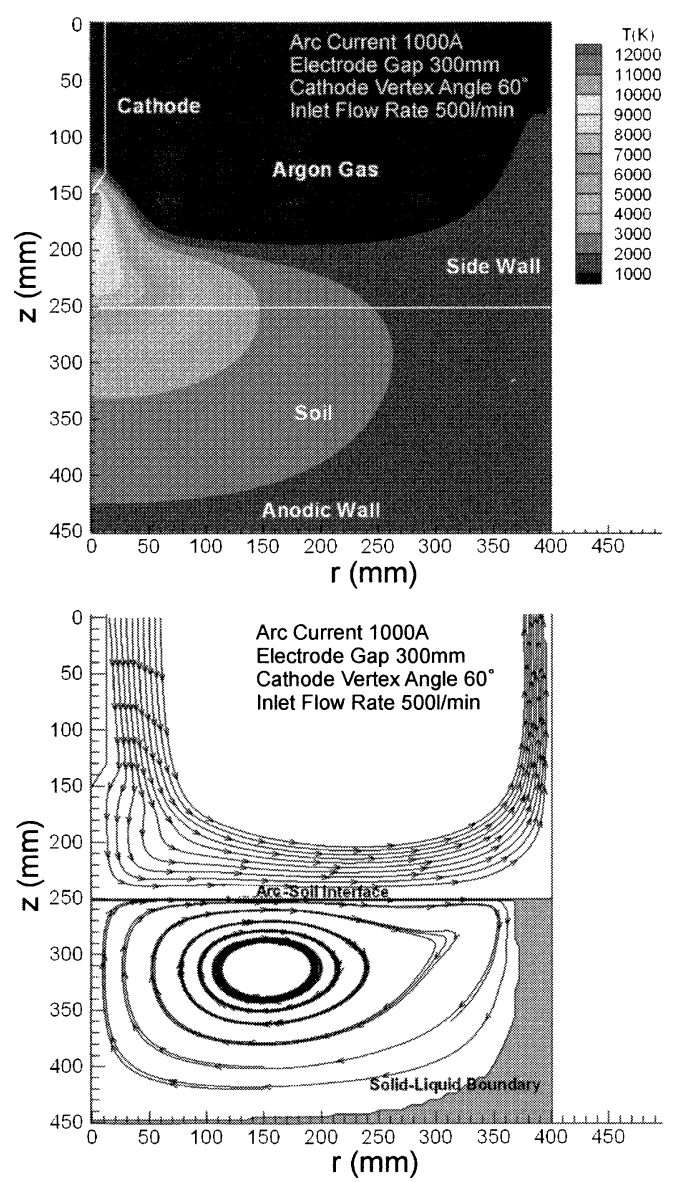

(a)
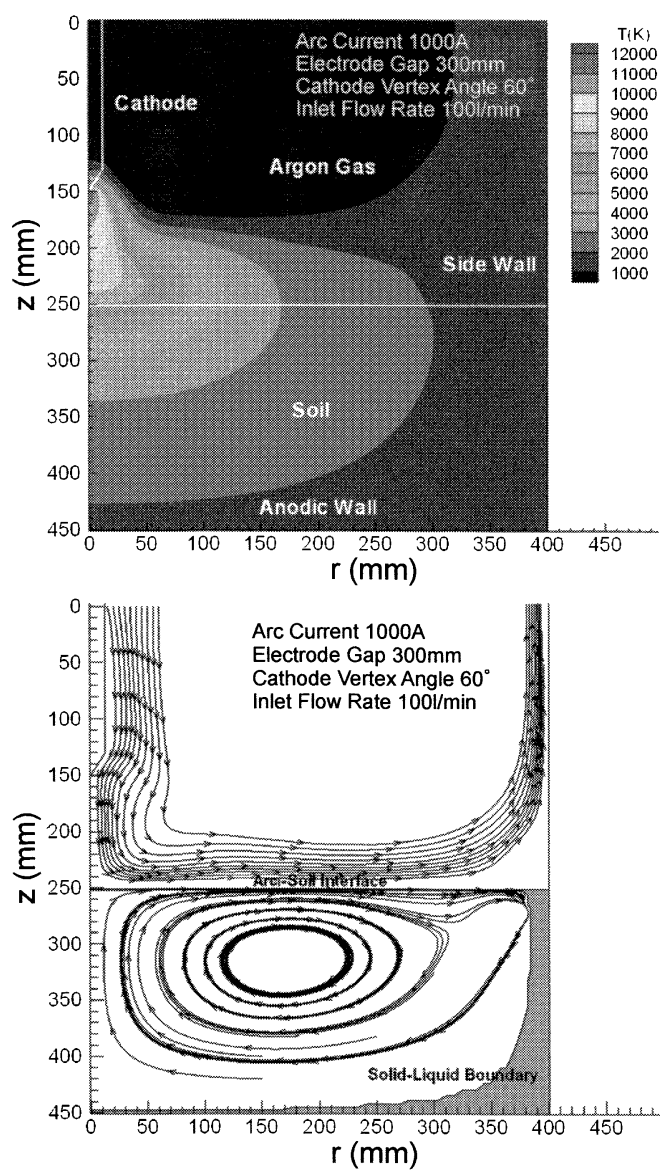

(b)
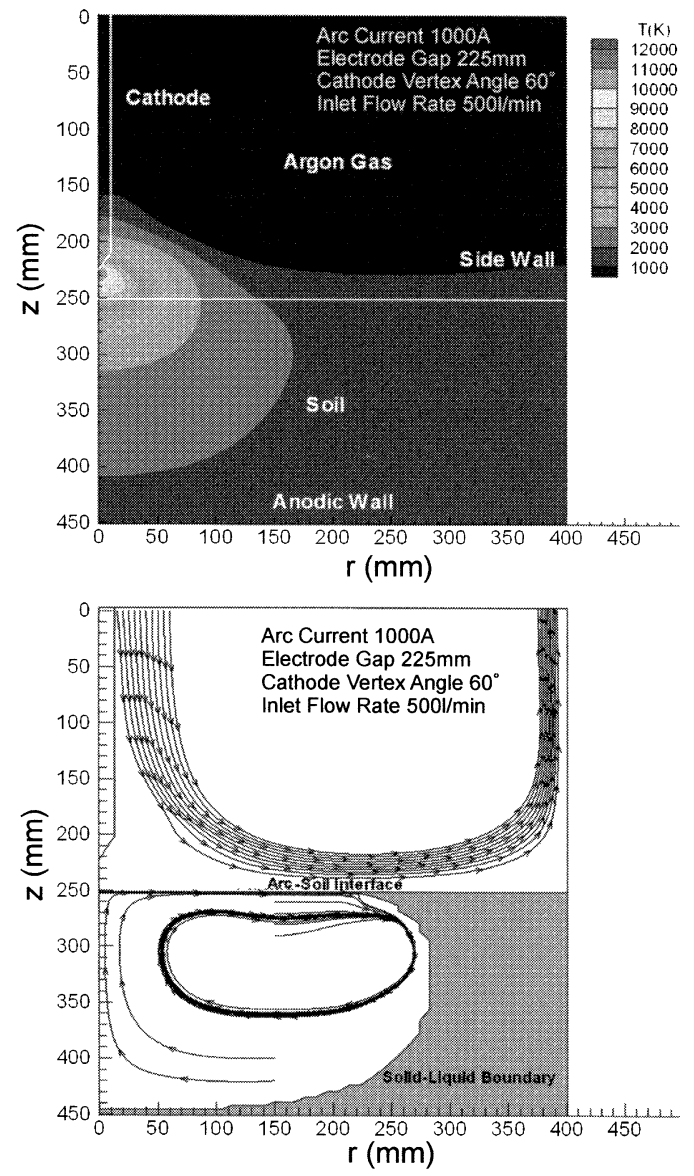

(b)
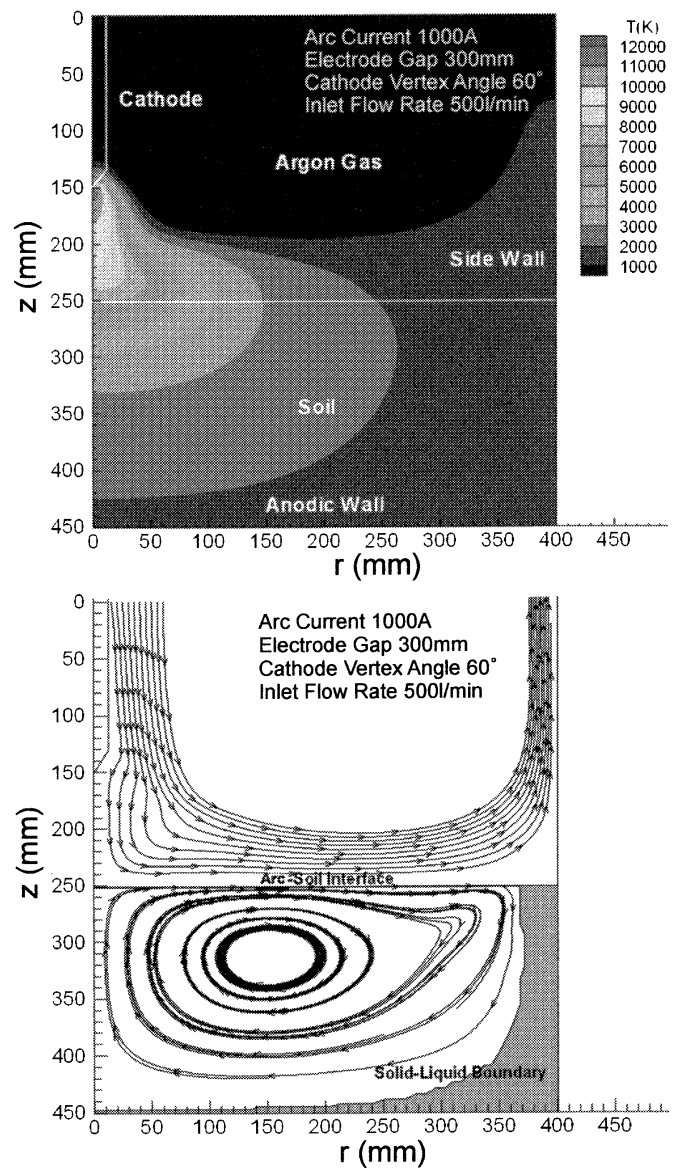

Fig. 3. Effect of electrode gap on isotherm, streamline, arc-soil interface and solidliquid boundary in the arc melter.
Fig. 4. Effect of inlet flow rate on isotherm, streamline, arc-soil interface and solidliquid boundary in the arc melter. 
(a)
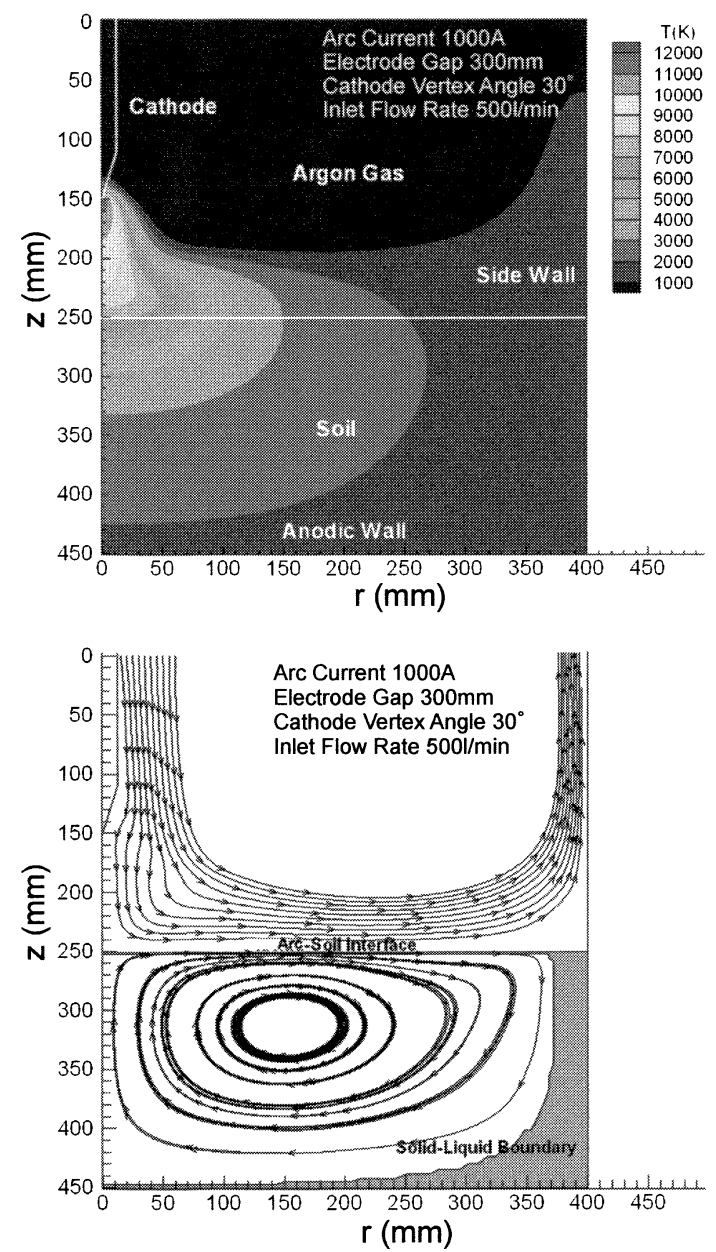

(b)
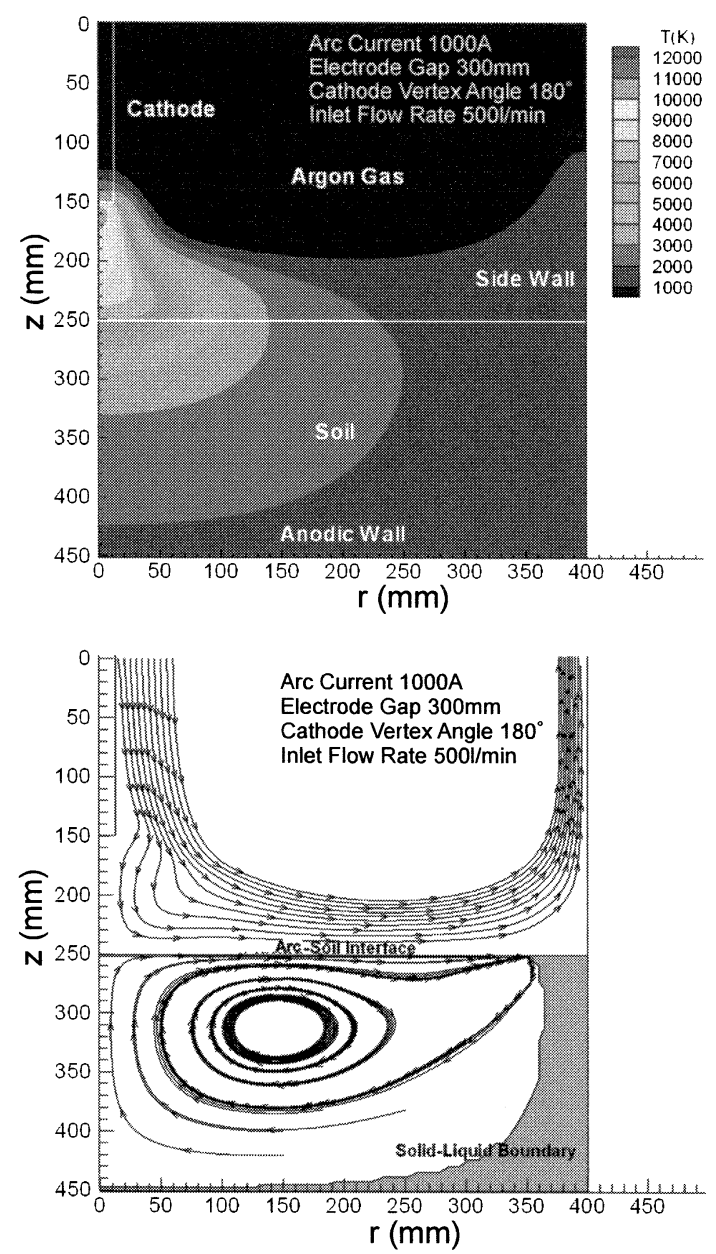

Fig. 5. Effect of cathode vertex angle on isotherm, streamline, arc-soil interface and solid-liquid boundary in the arc melter.

high temperature downward the cathode is suppressed in the case of larger inlet flow rate due to decrease in the net effective obtained enthalpy per volume, the melted soil region decreases compared with that in smaller inlet flow rate.

Figures 5(a) and 5(b) show the effect of the cathode vertex angle, 30 and $180^{\circ}$ on the ash melting process. In the case of $30^{\circ}$, the maximum temperature is increased locally near the cathode tip by Joule heating due to the current concentration. ${ }^{8)}$ Since the flow is less accelerated locally with decreasing cathode temperature under the cathode at $180^{\circ}$ the molten soil region decreases a little. However, there is an advantage of longer life time of electrode to melt nearly same volume of ash. ${ }^{8}$

Figure 6 shows radial velocity near arc-soil interface at $r=216.8 \mathrm{~mm}$. There is clearly large difference of tangential velocity between arc and soil near the interface. The radial velocity in the soil increases as the arc current increases since the electromagnetically induced plasma flow increases as the arc current increases. The radial velocity in the soil increases only for large electrode gap in the $1000 \mathrm{~A}$.

Figures 7(a) and 7(b) show the effect of applied arc current on soil heating efficiency for melting process and on volume fraction of melting soil to the total soil. Arc plasma power, radiation losses from cathode, arc-soil interface and

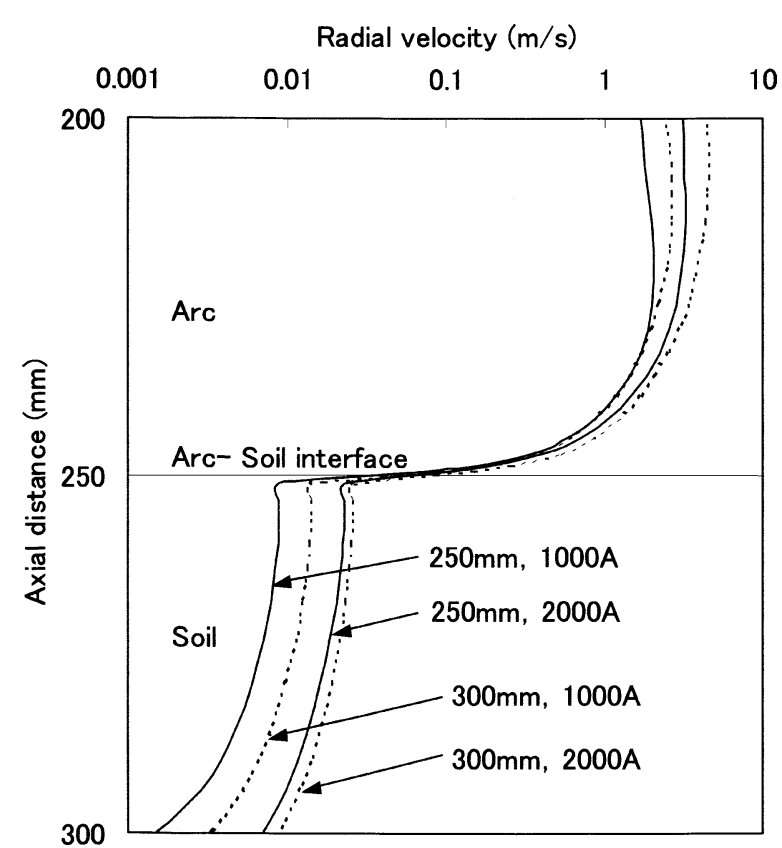

Fig. 6. Radial velocity near arc-soil interface. 

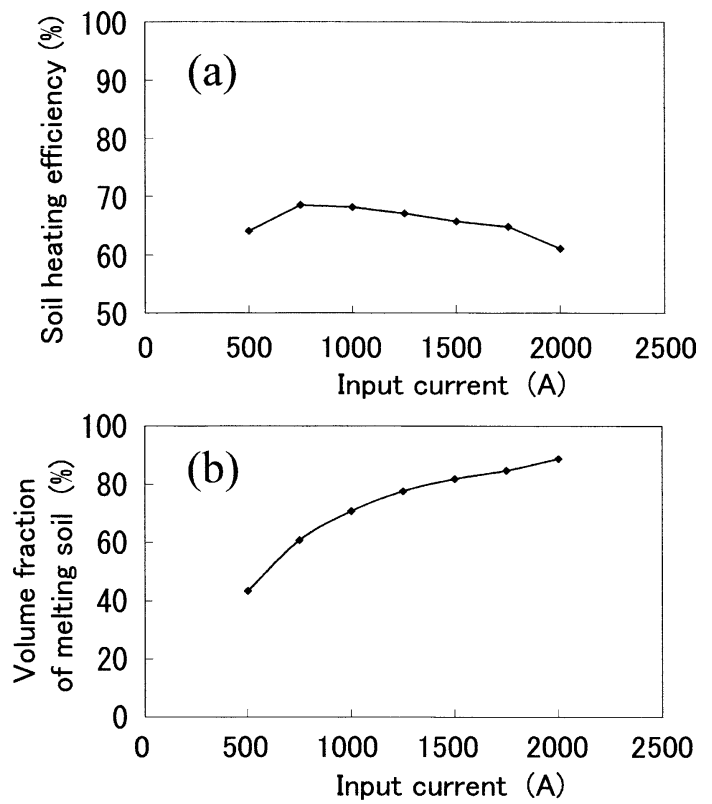

Fig. 7. Effect of arc current on soil heating efficiency and volume fraction of melting soil.
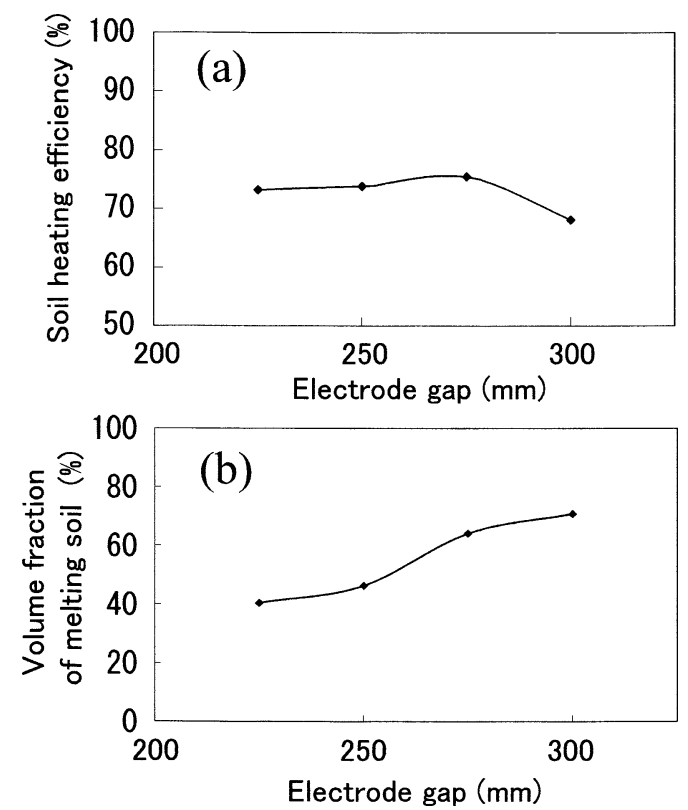

Fig. 8. Effect of electrode gap on soil heating efficiency and volume fraction of melting soil.

reactor wall and further heat loss from exhaust gas are not evaluated in the complex arc-ash melting heat transfer. Then, the soil heating efficiency is clearly defined as the ratio of the thermal condition to the arc-soil interface and Joule heating induced in the molten soil to input electric power of reactor. Here, the input electric power is the product of applied arc current and electric potential difference between the electrodes. The volume rate of melting soil increases with the input arc current at first but it finally saturates. On the other hand, the soil heating efficiency decreases gradually with the input arc current due to the relative saturation of Joule heating production.

Figures 8(a) and 8(b) show the effect of electrode gap on soil heating efficiency and on volume fraction of melting soil. When the electrode gap increases, a high temperature region spreads along the arc-soil interface. Then, the volume fraction of melting soil increases since heat conduction into the soil and convective heat transfer in the soil increase. However, the soil heating efficiency attains a maximum around the gap of $275 \mathrm{~mm}$ and then decreases suddenly at large electrode gap due to large heat loss from arc surface.

\section{Conclusion}

Numerical modeling is conducted for arc-ash melting systems by taking the complex interactions between arc and electrode, molten soil interface into account. The results obtained here by computational simulation are as follows:

(1) The impinging velocity and maximum temperature increase and then the high temperature region spreads along the arc-soil interface toward the side wall with increase in the input arc current and in the electrode gap due to the strong electromagnetic effects and active heat transfer processes in the arc and molten soil. In this case, melting volume fraction of soil increase, but the soil heating efficiency decreases.

(2) There exists the optimum input current for given molten soil volume fraction to obtain maximum energy conversion efficiency. It is effective to set the electrode gap as large as possible to produce the large arc volume within the stable arc generation.

(3) There are small effects of inlet flow rate and cathode vertex angle on the volume fraction of melting soil.

\section{Acknowledgements}

The present work was partly supported by Grant-in-aid for Scientific Research (B) from Japan Society of Promotion Science $(2001,2002)$. The numerical simulation was conducted by Origin2000 at Advanced Fluid Information Research Center, Institute of Fluid Science, Tohoku University.

\section{Nomenclature}

$B$ : Magnetic flux density $(\mathrm{T})$

$C_{\mathrm{p}}$ : Specific heat at constant pressure $(\mathrm{J} /(\mathrm{kg} \cdot \mathrm{K}))$

$e:$ Electron charge $(\mathrm{C})$

$h$ : Enthalpy $(\mathrm{J} / \mathrm{kg})$

$j: \quad$ Current density $\left(\mathrm{A} / \mathrm{m}^{2}\right)$

$k_{\mathrm{b}}$ : Boltzmann constant $(\mathrm{J} / \mathrm{K})$

$p:$ Pressure $(\mathrm{Pa})$

$Q: \quad$ Volume flow rate $(\mathrm{SL} / \mathrm{min})$

$R_{\mathrm{a}}: \quad$ Radiative loss $\left(\mathrm{J} / \mathrm{m}^{3}\right)$

$r$ : Radial coordinate $(\mathrm{m})$

$t$ : Time (s)

$T: \quad$ Temperature (K)

$u$ : Velocity in axial component $(\mathrm{m} / \mathrm{s})$

$v$ : Velocity in radial component $(\mathrm{m} / \mathrm{s})$

$z$ : Axial coordinate $(\mathrm{m})$

Greek symbols

$\phi: \quad$ Electric potential (V)

$\eta$ : Viscosity $(\mathrm{Pa} \cdot \mathrm{s})$

$\theta: \quad$ Cathode vertex angle (deg)

$\lambda$ : Thermal conductivity $(\mathrm{W} /(\mathrm{m} \cdot \mathrm{k}))$

$\mu_{0}:$ Permeability in vacuum $(\mathrm{H} / \mathrm{m})$

$\rho:$ Density $\left(\mathrm{kg} / \mathrm{m}^{3}\right)$ 


\section{$\sigma: \quad$ Electrical conductivity $(\mathrm{S} / \mathrm{m})$}

\section{Subscripts}

Ar: Argon

C: Cathode (Black lead)

$r$ : Radial component

Soil : Soil component

$\mathrm{z}$ : Axial component

$\theta:$ Azimuthal component

\section{REFERENCES}

1) T. Iwao, H. Miyazaki, T. Ishida, Y. Liu and T. Inaba: ISIJ Int., 40 (2000), 275.

2) Y. Liu et al.: Trans. Mater. Res. Soc. Jpn., 25 (2000), 381.

3) T. Inaba, Y. Watanabe, M. Nagano, T. Ishida and M. Endo: Thin Solid Films, 316 (1998), 111.

4) S. Paik, G. Hawkes and H. D. Nguyen: Plasma Chem. Plasma Process., 15 (1995), 677.
5) I. S. Kim and A. Basu: J. Mater. Process. Technol., 77 (1998), 17.

6) S. Paik and H. D. Nguyen: Int. J. Heat Mass Transfer, 38 (1995), 1161.

7) P. S. Wei and F. K. Chung: Metall. Mater. Trans. B, 31B (2000), 1387.

8) H. Nishiyama, T. Shimizu and T. Sato: Proc. of 2002 Symp. on Environmental Eng., (2002), 467.

9) H. Nishiyama, T. Sato and K. Takamura: ISIJ Int., 43 (2003), 950

10) J. Menart and L. Lin: J. Thermal Heat Trans., 12 (1998), 500.

11) M. I. Boulos, P. Fauchais and E. Pfender: Thermal Plasmas: Fundamentals and Applications, Vol.1, Plenum Press, New York, (1994), 388.

12) Hand Book of Chemistry, Fundamental II, ed. by Japan Chemical Engineering of Society, Maruzen, Tokyo, (1975), 985.

13) J. L. Beult and V. F. Fitzpatrick: In Situ Verification of Transuranic Waste: An Updated Systems Evaluation and Applications Assessment, PNL-4800 suppl-1, US-70, (1987).

14) J. B. Henderson: TPRL-1238, (1993)

15) S. V. Patankar: Numerical Heat Transfer and Fluid Flow, Hemisphere Pub. Corp., New York, (1980). 